\title{
Cuerpo, territorio y familia en las comunidades afrocolombianas residentes en Bogotá
}

\author{
Gigson Useche-Gonzalez
}

* Magíster en Educación, Universidad de la Sabana. Docente investigador, Universidad Libre, Bogotá, Colombia.

Correo electrónico:

gigson.usecheg@unilibrebog.edu.co

Recibido: 31 de marzo del 2014 Aprobado: 06 de noviembre del 2014

Cómo citar este artículo: Useche-González, Gigson. "Cuerpo, territorio y familia en las comunidades afrocolombianas residentes en Bogotá". Rastros Rostros 16.30 (2014): 119-127. Impreso. doi: http://dx.doi. org/10.16925/ra.v16i30.827

\begin{abstract}
Resumen
El presente artículo es el resultado de una investigación que se viene realizando dentro de la sublínea de investigación "La etnoeducación: un espacio para repensar la Educación en Colombia", vinculada a la Facultad de Educación de la Universidad Libre, y busca dar una caracterización del grupo étnico conformado por las comunidades afrodescendientes desplazadas en la actual coyuntura política, económica y social del país e insertadas precipitadamente al tejido social urbano, hecho que vulnera su calidad de vida, su desarrollo humano y afecta las dinámicas sociales urbanas. Esta situación amerita tanto la investigación como la intervención pedagógica en la búsqueda y materialización de propuestas educativas y planes de vida que contribuyan a la reconstrucción cultural y social de dichas comunidades étnicas.
\end{abstract}

Palabras clave: comunidades afrocolombianas, corporalidad, cuerpo, familia, territorio.

\section{Body, Territory and Family in Afro-Colombian Communities Residing in Bogotá}

\begin{abstract}
This article is the result of the research study being conducted in the sub-area of research titled "Ethnoeducation: A Space for Rethinking Education in Colombia", which is linked to the Faculty of Education at the Universidad Libre. It seeks to characterize the ethnic group made up of AfroColombian communities who are displaced in the country's current political, economic and social landscape, and who are hurriedly inserted into the urban social fabric, thus damaging their quality of life and human development, and affecting the urban social dynamics. This situation merits both research and pedagogical intervention in searching for and realizing educational proposals and life plans that contribute to the cultural and social rebuilding of these ethnic communities.
\end{abstract}

Keywords: afro-colombian communities, corporality, body, family, territory.

Corpo, território e família nas comunidades afro-colombianas residentes em Bogotá

Resumo

O presente artigo é o resultado de uma pesquisa que vem sendo realizada dentro da sub-linha de pesquisa "A Etnoeducação: um espaço para repensar a Educação na Colômbia", vinculada à Faculdade de Educação da Universidad Libre e procura dar uma caracterização do grupo étnico formado pelas comunidades afrodescendentes desplazadas na atual conjuntura política, econômica e social do país e inseridas precipitadamente ao tecido social urbano, feito que vulnera sua qualidade de vida, seu desenvolvimento humano e afeta as dinâmicas sociais urbanas. Essa situação merece tanto a pesquisa quanto a intervenção pedagógica na procura e na materialização de propostas educativas e planos de vida que contribuam para a reconstrução cultural e social de tais comunidades étnicas.

Palavras-chave: comunidades afro-colombianas, corporalidade, corpo, família, território. 


\section{Introducción}

El proyecto del que hace parte este artículo se propone estudiar aspectos que vulneran la integridad del ser individual, familiar y colectivo de las comunidades afrodescendientes radicadas en Bogotá. Se busca contribuir al desarrollo pleno de estas comunidades, en el marco de sus particularidades étnicas y culturales, lo que previene su posible disfunción familiar y social, derivada de la marginalidad material y la invisibilización cultural a que son sometidas en los espacios urbanos. Esto permite que la educación se constituya en un elemento indispensable para que la humanidad pueda progresar hacia los ideales de paz, libertad y justicia sociales.

Se espera, entonces, desde esta primera etapa de la investigación, abrir un espacio de reflexión científica, académica y de intervención, desde la interculturalidad en general y la etnomotricidad en particular, sobre una población específica, reconocida constitucionalmente por su diversidad étnica y cultural. Este espacio les permite usar el derecho natural y del ordenamiento legislativo que las particulariza y dota de derechos adicionales y concomitantes con su ancestralidad, estado en el que deben ser consideradas, reconocidas y tenidas en cuenta para su inserción y articulación en el tejido social, económico y cultural de la nación. Todo esto se da desde principios de respeto a la diversidad étnica y cultural del pueblo colombiano y de interculturalidad, que abre espacios para la convivencia armónica desde la diferenciación positiva.

Después de un largo proceso de luchas, que se inició desde el mismo momento en que las familias africanas fueron disueltas por el secuestro de los europeos, el más grande que se ha realizado en la historia de la humanidad, advierte Mosquera que:

El resurgimiento e implantación de la institución de la esclavitud en América para asegurar la explotación de la riqueza del continente con base en el secuestro, transporte infrahumano y esclavización de las personas africanas, fue una gran empresa económica, política, militar y religiosa de los Estados Imperiales europeos, y en el caso colombiano del Estado Imperial Español y sus sucesores, las familias de españoles criollos, dominantes y dueños absolutos del naciente Estado y la sociedad de la República de Colombia.

En este contexto, poblaciones enteras fueron trasladadas violentamente del África al continente americano. Esto ocasionó una ruptura de la estructura familiar y disolvió la comunicación entre los que hablaban una misma lengua, al separarlos y confinarlos en las casas o haciendas de sus amos. Sin embargo, el cimarronaje y la lucha de los palenques socavaron la empresa esclavista de los europeos hasta llegar a la abolición de la esclavitud. En Colombia, la esclavitud no está permitida, como lo manifiesta la Ley de Abolición:

Desde el día primero de enero de mil ochocientos cincuenta y dos serán libres todos los esclavos que existan en el territorio de la República. En consecuencia, desde aquella fecha gozarán de los mismos derechos y tendrán las mismas obligaciones que la Constitución y las leyes garantizan e imponen a los demás granadinos.

Como se muestra, los afrodescendientes han logrado el reconocimiento constitucional de sus derechos como grupo étnico. El Artículo Transitorio 55 de la Constitución de 1991, por primera vez en la historia de Colombia, considera la protección de la identidad cultural y los derechos de las comunidades negras, para el fomento de su desarrollo económico y social. Asimismo, en 1993, se expide la Ley 70 que reglamenta el Artículo 55 y determina que el Estado tendrá que velar porque en el sistema nacional educativo se conozca y difunda el conocimiento sobre las prácticas culturales propias de las comunidades y sus aportes a la historia y a la cultura colombiana, a fin de que ofrezcan una información equitativa y formativa de las sociedades y culturas de estas comunidades.

A diferencia de la legislación indígena, la Ley 70 enfatiza en la socialización y universalización de los contenidos estructurales de las culturas afrocolombianas, lo que amplía explícitamente el concepto de etnoeducación al oficializar la Cátedra de Estudios Afrocolombianos en el currículo (Decreto 1122 de 1998), según la cual la cultura de las comunidades afrocolombianas debe incorporarse obligatoriamente en los programas educativos de las ciencias sociales en los niveles de escolaridad preescolar, básica y en las facultades de educación.

El logro legislativo obtenido por las comunidades negras, expresado en la Ley 70 de 1993 y en el Decreto 1122 de 1998, que reglamenta el Artículo 39 de esta Ley, es el avance más significativo en lo que a multiculturalidad se refiere, en cuanto apunta a una lectura descentralizada de las culturas afrocolombianas, es decir abierta a la nación sin limitantes territoriales, étnicos, ni culturales. Esto permite una apertura realmente democrática al reconocimiento, la asimilación y la inclusión de un aún no dimensionado cuerpo de saberes y conocimientos científicos, inherentes a la diversidad. 
A partir del principio constitucional, expuesto en el artículo 67 de la Constitución, según el cual "corresponde al Estado regular y ejercer la suprema inspección y vigilancia de la educación con el fin de velar por su calidad y por el cumplimiento de sus fines", dentro de los que se priorizan los siguientes:

El deber de promover y fomentar el acceso a la cultura, por medio de la educación permanente y la enseñanza científica, técnica, artística y profesional en todas las etapas del proceso de creación de la identidad nacional ... [ya que] la cultura en sus diversas manifestaciones es fundamento de la nacionalidad, el Estado reconoce la igualdad y dignidad de todas las que conviven en el país y promoverá la investigación, la ciencia, el desarrollo y la difusión de los valores culturales de la nación. (70)

Igualmente, es importante para los afrocolombianos el reconocimiento constitucional de la diversidad religiosa, la unión conyugal libre, la despenalización de la bigamia, pues antes de que eso pasara se estaba atentando contra sus prácticas de familia extensa y las disposiciones de protección para las mujeres cabeza de hogar.

En cuanto a los aspectos conceptuales, la dimensión teórica que fundamentó el proyecto es la axiológica, ya que su fin último se circunscribe a la generación de un proceso que atraviese trasversalmente el marco disciplinar de la educación física y las ciencias sociales y propicie los espacios para el desarrollo de una convivencia ciudadana sustentada en valores como la tolerancia, la solidaridad, la equidad y el respeto a los derechos fundamentales del ser humano.

Por otra parte, desde la concepción teórica que concibe el cuerpo como una construcción social y cultural:

Muy, pero muy, ligado a las grietas de la episteme y de la subjetividad heredada de la ilustración, está el problema de la cartografía de nuestros cuerpos. Si entendemos por construcción social de una realidad, el complejo proceso mediante el cual nos representamos y significamos socialmente algo ... es claro que las cartografías de nuestro cuerpo son el resultado de una construcción familiar en primer lugar y luego social. (Olson y Sameroff 154)

[De la territorialidad que ocupa] el cuerpo humano, como territorio donde se encarna el yo, es dominio de Gea (Gaia), la diosa de la tierra y madre de todas las cosas. Quizá por esta razón, el cuerpo, con sus convexi- dades (masas más o menos ectópicas) y concavidades (depresiones, valles angostos, orificios que conducen a oscuras profundidades) ha sido descrito metafóricamente como una geografía, que incita a recorrer y explorar sus límites, como un paisaje, o como un 'huerto cerrado' (Cantar de los Cantares 4,12).

Se suscitan, entonces, las preguntas sobre cómo se construyen los cuerpos en las nuevas territorialidades de la ciudad, las familias y las comunidades étnicas, con qué elementos esto se hace (memoria, identidad, cultura, olvido), a través de qué mecanismos (acciones políticas, sociales, culturales, y resistencias pasivas o activas), produciendo nuevos escenarios de interacción y convivencia, y, por último, la de si estos espacios viabilizan la interculturalidad o, por el contrario, se transforman en nuevos espacios de segregación, discriminación o exclusión.

Esta problemática, que condensa sus efectos en la convivencia ciudadana, se sintetiza tentativamente, desde el diagnóstico y la investigación que sustentan la propuesta, en los siguientes términos: la población afrocolombiana desplazada conserva, a través de los lazos familiares y de parentela, como único patrimonio para la elaboración de sus identidades y sus proyectos colectivos de vida, sus cuerpos, su memoria etnomotriz, ${ }^{1}$ el cuerpo de contenidos étnico-culturales transmitidos generacionalmente a través de la interrelación familiar y comunitaria. Estos contenidos se ven cotidianamente reprimidos y obstaculizados por la discriminación e intolerancia de la población urbana en los diferentes sectores y espacios de convivencia. Esto se debe a la permanencia de rezagos ideológicos racistas, que se acrecientan por la difusión de una mentalidad extranjerizante, a través del sistema educativo, los medios de comunicación y los espacios de socialización. De esta manera, resulta difícil para las comunidades afrocolombianas elaborar sus planes de vida propios, por los que pueda articularse a la sociedad urbana sin perder sus principios de vida, su herencia étnica-cultural y sus intereses colectivos.

En el continente que les tocó vivir, los pueblos ancestrales construyeron concepciones del cuerpo ligadas a sus cosmologías y a los territorios que habitaron. Estas eran ricas en imágenes e íconos que, posteriormente, se mezclan con las ideas que traen consigo los europeos al momento de la conquista y que son, pre-

\footnotetext{
1 La palabra etnomotriz hace referencia a la acción motriz propia de cada etnia que se registra como memoria de un movimiento natural propio: caminar, lanzar, asir, rolar, girar, dormir...
} 
cisamente como afirma Rafael Ávila, los postulados de sus filósofos y, posteriormente, de los científicos. Estos se encargaron de producir y suministrar imágenes del ser humano y de su cuerpo. En nuestro medio, hemos estado dominados por una concepción dualista, mientras que en Oriente y en las comunidades indígenas tienen una concepción monista y dinámica. Platón, Aristóteles, Tomás de Aquino y Descartes son variaciones del dualismo antropológico y, por supuesto, han sido las fuentes suministradoras de concepciones dualistas que, hoy por hoy, son las concepciones dominantes, reforzadas por la teología cristiana occidental.

En un país como el nuestro, en el que comunidades se encuentran en permanente desplazamiento desde la violenta conquista europea:

Donde abundan los desplazados, sabemos que el desplazamiento es una consecuencia de un acto de ocupación militar que despoja a las víctimas de sus tierras y de sus recursos, desquebraja la estructura familiar. Con el cuerpo ha pasado algo parecido en la construcción de políticas y currículos oficiales. Ha sido "desplazado" como consecuencia de un acto de ocupación por parte de cartografías unidimensionales que lo han despojado de sus escenarios de actuación. La selección y privilegiación de las disciplinas de estilo Galileano, un arbitrario cultural, como diría Pierre Bourdieu, lo ha empujado hacia los márgenes y lo ha reducido a la condición de cuerpo in-visible e in-significante. (Osorio 22)

Podemos afirmar que el cuerpo lúdico, del goce estético, del placer, ha salido por la puerta de atrás y con él, igualmente, el cuerpo erótico, el cuerpo eurítmico, el cuerpo melódico, el cuerpo dramatúrgico, el cuerpo mímico, el cuerpo gimnástico. En su lugar, encontramos entronizadas, como fetiches sagrados, una ideología laboralista que lo reduce a una fuerza de producción, una ideología esteticista que lo reduce a objeto de remodelación estética, una ideología bodytech que lo reduce a objeto de ensanchamiento muscular, e incluso una ideología cientificista según la cual, el cuerpo solamente tiene sentido como soporte del cerebro o de la razón ilustrada.

\section{Metodología}

El tipo de investigación corresponde a un estudio documental y, para su realización, se utilizó la metodología de los estados del arte. En este caso, el estado fue sobre los temas del cuerpo, el territorio y la familia de los afrocolombianos residentes en Bogotá.
Para realizar un estado del arte, es necesario aproximarse a las fuentes documentales, es decir, hacer una investigación de lo conocido para proceder a la organización de los materiales, para establecer la relación y conexión en las temáticas que se presentan en dichos documentos, añadiendo los enfoques que se tienen en cuenta dentro del estado del arte, que son entendidos en dos fases:

1. Fase heurística: se inicia la búsqueda y recopilación de las fuentes de información, que pueden ser de muchas características y diferente naturaleza.

2. Fase hermenéutica: en esta, cada una de las fuentes investigadas se deberá leer, analizar, interpretar y clasificar, dependiendo su importancia dentro del trabajo de investigación.

\section{Procedimiento}

La construcción del estado del arte requiere de unos pasos específicos (figura 1).

\section{Avance de resultados}

En la fase de diseño se crearon las condiciones académicas y operativas del proyecto y para la toma de decisiones en la conformación del equipo de trabajo, en este caso, con la sublínea de investigación de la Universidad Libre de Bogotá "La etnoeducación: un espacio para repensar la educación en Colombia”. Luego se determinó el software que se utilizaría para la base de datos, el inventario de las unidades documentales y se establecieron los criterios para el rastreo y localización de los documentos. Para esta primera parte, se hizo un seguimiento en los centros de documentación y bibliotecas mayores de la ciudad de Bogotá. Así, pues, se reseñaron algunos de los materiales encontrados en estos lugares en los que hay acceso abierto al público.

En la fase de exploración, se realizó un balance inicial de los materiales y ejemplares encontrados, para construir un sistema categorial con el cual se pudieron depurar efectivamente los documentos disponibles. Para esta fase también se consultaron las bases de datos vía internet de otros países. Los criterios para el rastreo de los ejemplares fueron libros o documentos referidos a los temas de cuerpo, territorio, afrocolombianos, género.

En la fase de focalización, se encontraron varios títulos de obras referentes a contextos familiares, género, culturales, artísticos, políticos, geográficos, antropológicos, y pedagógicos. 


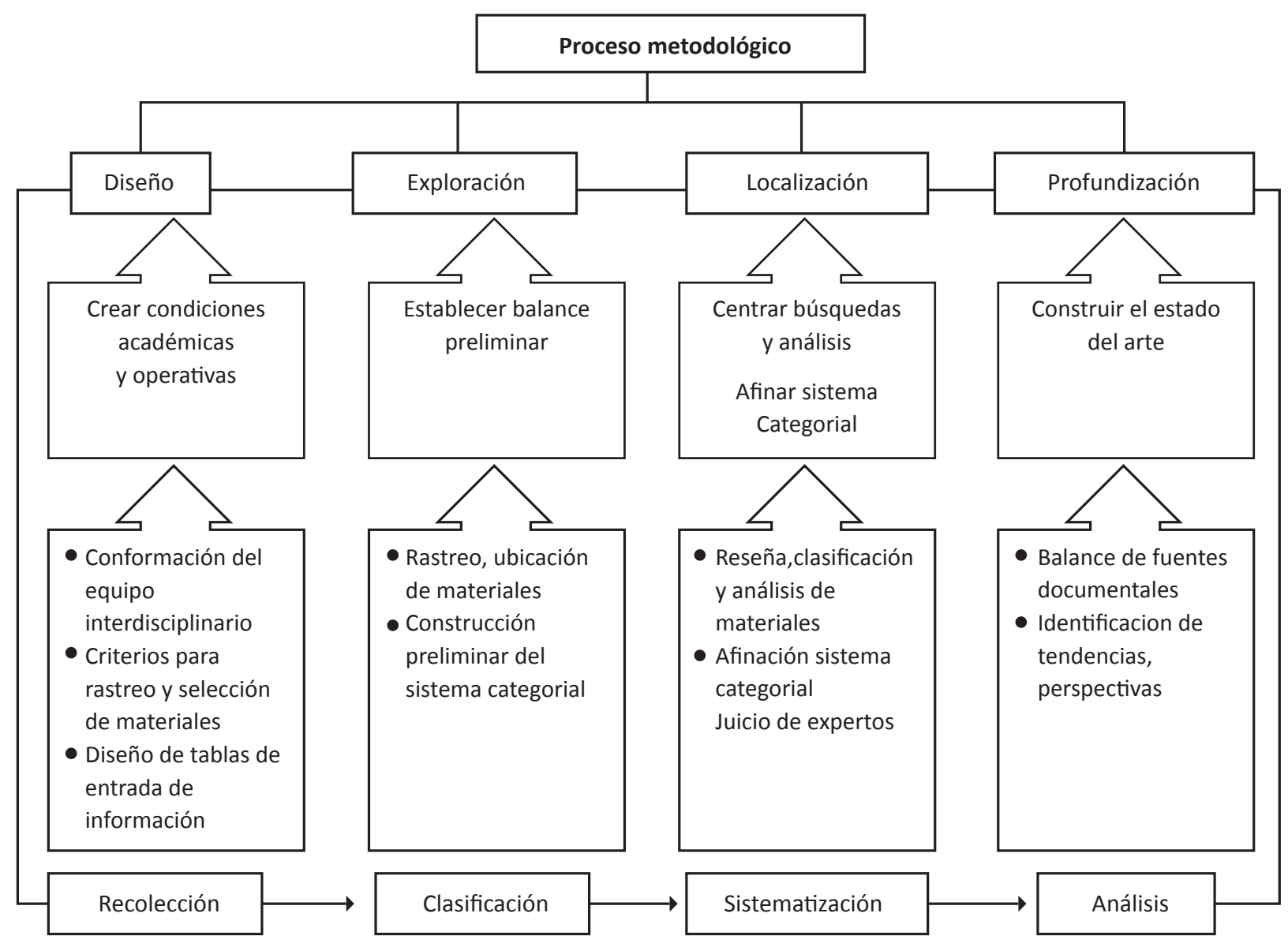

Figura 1. Proceso metodológico tomado como referente para la construcción del estado del arte.

Fuente: Vélez, Olga Licia, y María Eumelia Galeano. Investigación cualitativa. Medellín: Universidad de Antioquia, 2000.

En la fase de profundización, la construcción del estado del arte abarcó la recopilación, ordenamiento y la clasificación de las fuentes consultadas para poder establecer conexiones entre estas como tendencias, enfoque, concepciones, invisibilización, colonización del cuerpo y del territorio, hegemonización cultural, memoria, olvido, identidad, género y terror (tabla 1).

\section{Algunos comentarios del avance de los resultados}

La investigación estuvo fundamentada en la hipótesis de trabajo, según la cual la fractura familiar, la crisis de valores se manifiestan en conductas racistas y discriminatorias, que se traducen en comportamientos hostiles e insolidarios hacia la mal llamada minoría de población afrocolombiana residente en Bogotá, y se deben a la invisibilización de la diversidad étnica, cultural y regional inherente a la nación colombiana.
Este último fenómeno imposibilita que dichas comunidades construyan y gestionen de manera autónoma y colectiva sus proyectos o planes de vida, en los que puede tener cabida la interculturalidad, la etnoeducación así como la gran riqueza de su expresión corporal.

La primera etapa de la investigación pretende brindar a dichas comunidades asesoría y acompañamiento en la construcción de sus planes de vida y de sus proyectos de vida a partir de la recuperación de los saberes y valores propios de las culturas afrocolombianas, desde una perspectiva etnoeducativa y multicultural, lo que propicia un proceso de investigación participativo. El cumplimiento de este objetivo propenderá por el desarrollo de competencias axiológicas, comunicativas, éticas, corporales y estéticas tanto en los estudiantes e investigadores como en las comunidades afrocolombianas. Estos elementos, a mediano plazo, propiciarán, por un lado, el mejoramiento de la convivencia ciudadana y, por otro, la consolidación de los 
Tabla 1. Listado de documentos

\begin{tabular}{|c|c|c|c|c|}
\hline Autor principal & Títulos & Materias & Artículos y ponencias & Edición y año \\
\hline Inírida Morales Villegas & $\begin{array}{l}\text { Mujer negra, mirar del otro y resis- } \\
\text { tencias. Nueva Granada siglo xviII }\end{array}$ & Género y libertad & $\begin{array}{l}\text { Memoria y Sociedad N. } \\
15\end{array}$ & Noviembre, 2003 \\
\hline $\begin{array}{l}\text { Marisa Braylan } \\
\text { compiladora }\end{array}$ & $\begin{array}{l}\text { Exclusión e inclusión. El problema } \\
\text { de los colectivos discriminados }\end{array}$ & $\begin{array}{l}\text { Discriminación de } \\
\text { la mujer negra Pág. } \\
19-30\end{array}$ & $\begin{array}{l}\text { Centro de Estudios Socia- } \\
\text { les DAIA }\end{array}$ & $\begin{array}{l}\text { Marcelo Kohan, no- } \\
\text { viembre, } 2010\end{array}$ \\
\hline Carlos Trosman & El cuerpo: un estado soberano & & $\begin{array}{l}\text { http://www.topia.com.ar/ } \\
\text { articulos/el-cuerpo-un- } \\
\text { estado-soberano }\end{array}$ & 29 abril de 2004 \\
\hline $\begin{array}{l}\text { Lucrecia Piedrahita } \\
\text { Orrego }\end{array}$ & El cuerpo como territorio & Corporalidad & $\begin{array}{l}\text { Ruta en Estudios Estéticos } \\
\text { EAFIT: cuerpo y territoriol } \\
\text { El cuerpo como territo- } \\
\text { rio - Periódico Estudiantil } \\
\text { Nexos }\end{array}$ & 2010 \\
\hline Kosme de Barañano & $\begin{array}{l}\text { Isabel Muñoz: detalles y miradas o } \\
\text { los cuerpos como territorio }\end{array}$ & Corporalidad & $\begin{array}{l}\text { Art-Signal Contemporany } \\
\text { Art Magazine }\end{array}$ & Etiopía, 2002 \\
\hline Sergio Ferrari & $\begin{array}{l}\text { Colombia: la tierra, humus para } \\
\text { la paz }\end{array}$ & Comunidad & $\begin{array}{l}\text { Ecoportal Dedo y llaga } \\
0348\end{array}$ & 8 febrero de 2011 \\
\hline Libia Grueso Castelblanco & $\begin{array}{l}\text { Comunidades negras: el derecho a } \\
\text { ser diferentes }\end{array}$ & Comunidad & N. ${ }^{\circ} 14$ Vol. 4 & 2006 \\
\hline $\begin{array}{l}\text { Gloria Caray Ariza y } \\
\text { Mará Viveros Vigoya }\end{array}$ & El cuerpo y sus significados & Corporalidad & $\begin{array}{l}\text { Cuerpo, diferencias y } \\
\text { desigualdades }\end{array}$ & $\begin{array}{l}\text { VIII Congreso Antro- } \\
\text { pología en Colombia, } \\
\text { Bogotá, } 1999\end{array}$ \\
\hline Hoffmann, Odile, & $\begin{array}{l}\text { Del territorio étnico a la ciudad: las } \\
\text { expresiones de identidad negra en } \\
\text { Colombia a principios del siglo xxI }\end{array}$ & Territorio & $\begin{array}{l}\text { Territorio y cultura. } \\
\text { Territorios de conflicto y } \\
\text { cambio sociocultural, pp. } \\
277-307\end{array}$ & $\begin{array}{l}\text { Universidad de Caldas, } \\
\text { Manizales, Colombia. } \\
2002\end{array}$ \\
\hline Mario Diego Romero & $\begin{array}{l}\text { Ante el deterioro de la cultura } \\
\text { afrocolombiana: ¡Hay que tomar } \\
\text { medidas! }\end{array}$ & Afrocolombianidad & Artículo, Agencia AUPEC. & 25 de marzo de 1998 \\
\hline $\begin{array}{l}\text { Santiago Arboleda } \\
\text { Quiñónez }\end{array}$ & $\begin{array}{l}\text { Conocimientos ancestrales ame- } \\
\text { nazados y destierro prorrogado: la } \\
\text { encrucijada de los afrocolombianos }\end{array}$ & Afrocolombianidad & $\begin{array}{l}\text { Artículo. www. } \\
\text { bdigital.unal.edu. } \\
\text { co/1237/18/17CAPI16.pdf }\end{array}$ & \\
\hline $\begin{array}{l}\text { Olivier Barbary; } \\
\text { Fernando Urrea }\end{array}$ & $\begin{array}{l}\text { La población negra en la Colombia } \\
\text { de hoy: dinámicas sociodemográfi- } \\
\text { cas, culturales y políticas }\end{array}$ & Territorio & $\begin{array}{l}\text { Estudios afro-asiáticos Vol. } \\
25 \mathrm{~N} .^{\circ} 1\end{array}$ & $\begin{array}{l}\text { Rio de Janeiro, Brasil, } \\
2003\end{array}$ \\
\hline Mario Diego Romero & $\begin{array}{l}\text { Familia afrocolombiana y construc- } \\
\text { cion territorial en el pacífico sur, } \\
\text { siglo xviII }\end{array}$ & Territorio & $\begin{array}{l}\text { Geografía humana de } \\
\text { Colombia, Tomo vi: los } \\
\text { afrocolombianos }\end{array}$ & $\begin{array}{l}\text { Biblioteca virtual Banco } \\
\text { de la República, } 29 \text { de } \\
\text { noviembre de } 2004\end{array}$ \\
\hline $\begin{array}{l}\text { Yobenj Aucardo } \\
\text { Chicangana Bayona }\end{array}$ & $\begin{array}{l}\text { El nacimiento del caníbal: un debate } \\
\text { conceptual }\end{array}$ & Territorio & $\begin{array}{l}\text { Historia crítica N. }{ }^{\circ} 36, \mathrm{pp} \text {. } \\
150-173\end{array}$ & $\begin{array}{l}\text { Bogotá, julio-diciembre. } \\
2008\end{array}$ \\
\hline Wania santanna & $\begin{array}{l}\text { Hacia una percepción de género } \\
\text { y raza }\end{array}$ & $\begin{array}{l}\text { Identidad de la mu- } \\
\text { jer: teoría y análisis }\end{array}$ & Revista especial/fempress & Brasil, 1995 \\
\hline $\begin{array}{l}\text { Alcaldía de Santo Tomás, } \\
\text { Atlántico }\end{array}$ & $\begin{array}{l}\text { Cuerpo y territorio: reflexiones } \\
\text { sobre conflictos de biopoder }\end{array}$ & Cuerpo & $\begin{array}{l}\text { Laboratorios de Inves- } \\
\text { tigación-Creación del } \\
\text { Ministerio de Cultura }\end{array}$ & $\begin{array}{l}\text { Santo Tomás, Atlántico, } \\
4-5 \text { de septiembre, } 2010\end{array}$ \\
\hline Ministerio de Cultura & $\begin{array}{l}\text { Laboratorio de Mediación/Creación } \\
\text { Movimiento y ritmo }\end{array}$ & Cuerpo y arte & $\begin{array}{l}\text { Convocatoria Laboratorio } \\
\text { de Mediación/Creación } \\
\text { para el Atlantico }\end{array}$ & $\begin{array}{l}\text { Barranquilla, } 13 \text { de } \\
\text { agosto } 2010\end{array}$ \\
\hline Juan Álvaro Echeverri & $\begin{array}{l}\text { Territorio como cuerpo y territorio } \\
\text { como naturaleza: ¿diálogo inter- } \\
\text { cultural? }\end{array}$ & $\begin{array}{l}\text { Semántica del } \\
\text { territorio }\end{array}$ & $\begin{array}{l}\text { A. Surrallés \& P. García } \\
\text { Hierro (eds.), Documento } \\
\text { N. }{ }^{\circ} 39 \text {, pp. } 259-275\end{array}$ & Copenhague, 2004 \\
\hline
\end{tabular}


(viene)

\begin{tabular}{|c|c|c|c|c|}
\hline Autor principal & Títulos & Materias & Artículos y ponencias & Edición y año \\
\hline Рвот Puerto Tejada & Territorio étnico afrocolombiano & Territorio & $\begin{array}{l}\text { Documento resumen } \\
\text { PBOT Municipio Puerto } \\
\text { Tejada, Cauca }\end{array}$ & 2004 \\
\hline CEUNA & Afrocolombianidad y género & Género & $\begin{array}{l}\text { http://alainet.org/ } \\
\text { active/20458\&lang=es }\end{array}$ & $2007-11-01$ \\
\hline Gustavo Chirolla & $\begin{array}{l}\text { La relación arte y territorio: aproxi- } \\
\text { maciones a una geoestética a partir } \\
\text { de Deleuze y Guattari }\end{array}$ & Territorio & & \\
\hline Victoria Sendón de León & $\begin{array}{l}\text { El cuerpo como territorio de } \\
\text { soberanía }\end{array}$ & Territorio & $\begin{array}{l}\text { ebs.uvigo.es/xenero/pro- } \\
\text { fesorado/purificacion.../ } \\
\text { cuerpo.pdf }\end{array}$ & \\
\hline $\begin{array}{l}\text { Luz Adriana Maya } \\
\text { Restrepo }\end{array}$ & $\begin{array}{l}\text { Brujería y reconstrucción étnica } \\
\text { de los esclavos del Nuevo Reino de } \\
\text { Granada, siglo xviI }\end{array}$ & Cultura & $\begin{array}{l}\text { Geografía humana de } \\
\text { Colombia: los afrocolom- } \\
\text { bianos }\end{array}$ & $\begin{array}{l}\text { Instituto Colombiano } \\
\text { de Antropología e } \\
\text { Historia ICANH }\end{array}$ \\
\hline Silvio de Gracia & $\begin{array}{l}\text { Arte acción en Latinoamérica: } \\
\text { cuerpo político y estrategias de } \\
\text { resistencia }\end{array}$ & Corporalidad & $\begin{array}{l}\text { revista.escaner.cl/taxo- } \\
\text { nomy/term/15 }\end{array}$ & 29 de octubre, 2010 \\
\hline Ulrich Oslender & $\begin{array}{l}\text { Geografías del terror: un marco de } \\
\text { análisis para el estudio del terror }\end{array}$ & Terror & $\begin{array}{l}\text { X Coloquio Internacional } \\
\text { de Geocrítica: diez años de } \\
\text { cambios en el mundo, en la } \\
\text { geografía y en las ciencias } \\
\text { sociales, 1999-2008 }\end{array}$ & $\begin{array}{l}\text { Barcelona, } 26-30 \text { de } \\
\text { mayo de } 2008\end{array}$ \\
\hline Juana Chaves Castaño & $\begin{array}{l}\text { Cuerpo, poder y territorio en } \\
\text { rituales y prácticas funerarias del } \\
\text { conflicto armado colombiano: un } \\
\text { análisis antropológico de algunos } \\
\text { municipios en Caldas y Risaralda }\end{array}$ & Antropología & $\begin{array}{l}\text { Rev. Eleuthera. Vol. 4, } \\
\text { enero - diciembre 2010, pp. } \\
230-249\end{array}$ & Enero, 2010 \\
\hline $\begin{array}{l}\text { Libia Rosario Grueso } \\
\text { Castelblanco }\end{array}$ & $\begin{array}{l}\text { El derecho de las comunidades afro- } \\
\text { colombianas a la consulta previa, } \\
\text { libre e informada }\end{array}$ & Derecho & $\begin{array}{l}\text { http://www.acnur.org/ } \\
\text { biblioteca/pdf/7653. } \\
\text { pdf?view=1 }\end{array}$ & $\begin{array}{l}\text { Naciones Unidas, Dere- } \\
\text { chos humanos }\end{array}$ \\
\hline $\begin{array}{l}\text { Santiago Arboleda } \\
\text { Quiñonez y Otros }\end{array}$ & $\begin{array}{l}\text { Afro-reparaciones: memorias de la } \\
\text { esclavitud y justicia reparativa para } \\
\text { negros, afrocolombianos y raizales }\end{array}$ & Antropología & $\begin{array}{l}\text { www.bdigital.unal.edu. } \\
\text { co/1237/ }\end{array}$ & \\
\hline $\begin{array}{l}\text { Rosa Bermúdez, Enrique } \\
\text { Jaramillo, Luis Fernando } \\
\text { Barón y Ana Lucía Paz }\end{array}$ & Poblaciones y territorios en disputa & Derecho & $\begin{array}{l}\text { https://bibliotecadigital. } \\
\text { icesi.edu.co/...digital/.../ } \\
\text { territorios_disputa.pdf }\end{array}$ & $\begin{array}{l}\text { Universidad Icesi, Cali, } \\
\text { Colombia, } 2009\end{array}$ \\
\hline $\begin{array}{l}\text { Rosa Emilia Bermúdez } \\
\text { Rico }\end{array}$ & Gobernabilidad y control territorial & Política & $\begin{array}{l}\text { bibliotecadigital.icesi.edu. } \\
\text { co/biblioteca_digital/.../1/ } \\
\text { capitulo1.pdf }\end{array}$ & $\begin{array}{l}\text { Universidad Icesi, Cali, } \\
\text { Colombia, } 2010\end{array}$ \\
\hline $\begin{array}{l}\text { Aída Carolina Lanche- } \\
\text { ros, Julián Ruiz y Andrés } \\
\text { Rincón Ortiz }\end{array}$ & Bojayá: entre el miedo y los medios & Política & $\begin{array}{l}\text { www.scribd.com }>\text { Re- } \\
\text { search }>\text { History }\end{array}$ & 26 de abril, 2011 \\
\hline Hildegarda de Bingen & $\begin{array}{l}\text { Cuerpo y corporalidad neurociencia } \\
\text { y neurocultura }\end{array}$ & $\begin{array}{l}\text { Neurociencia } \\
\text { Neurocultura }\end{array}$ & $\begin{array}{l}\text { http://pacotraver.word- } \\
\text { press.com/2009/04/05/ } \\
\text { cuerpo-y-corporalidad/ }\end{array}$ & Abril 05 de 2009 \\
\hline
\end{tabular}

Fuente: elaboración propia.

proyectos de vida propios de dichas comunidades, sustentados en unas relaciones sociales de tolerancia, respeto y asimilación positiva de las diferencias.

Bogotá recibe a una numerosa población de indígenas, afrocolombianos y campesinos, que diariamente está siendo desplazada de sus regiones de origen por la violencia política en sus diferentes matices de confron- tación. Esta población es portadora de la herencia étnica y cultural, cuya importancia en la construcción de la identidad nacional ha sido históricamente negada. Ante este fenómeno migratorio, la sociedad capitalina ha asumido conductas discriminatorias y racistas, que por su impacto han sensibilizado incluso a los medios de comunicación. "Costeños, chocoanos, tumaqueños, 
urabenses conforman la población negra de Suba: cerca de 2000 viven en el suroccidente de esa localidad" o "Los hijos del racismo" son algunas de las investigaciones periodísticas que dan cuenta de la crisis de valores en la sociedad capitalina, sintetizada por Marisol Gómez en los siguientes términos: "El jardín infantil, ubicado al sur de la ciudad, [Barrio Britalia] es hoy el botón de muestra de la discriminación que sufre el migrante negro en Bogotá. El distrito reconoce que no tiene políticas definidas para la comunidad afrocolombiana" (78).

Esta crisis de valores se hace manifiesta en conductas de intolerancia y discriminación hacia la población afrocolombiana residente en la capital, y se debe a la permanencia de un discurso de invisibilización de la diversidad étnica, cultural y regional de la nación, no obstante los dictámenes constitucionales y su reglamentación para los diversos campos de la vida social. Desde esta perspectiva, el proyecto busca propiciar el acercamiento a las comunidades afrocolombianas de Bogotá, para el diagnóstico de sus necesidades motrices y el acompañamiento y asesoría en la elaboración de sus proyectos de vida.

\section{Conclusiones}

A pesar de la institucionalización de conceptos como multietnicidad, pluriculturalidad y etnoeducación, que apuntan a la materialización y el cumplimiento de los postulados de la Constitución Política de Colombia, se constata la existencia de una realidad contraria. La sociedad urbana continua adoleciendo de una visión totalitaria de la realidad nacional; aún persiste el desconocimiento de la diversidad étnica, regional y cultural, que acentúa negativamente la asimilación de la diversidad como elemento constitutivo de la identidad nacional, como en los tiempos coloniales cuando factores como la raza, la riqueza y la procedencia determinaban el estatus de los individuos y la consecuente pormenorización de los colectivos étnicos y culturales.

Esta situación se debe, en gran medida, a que tanto la educación como los medios de comunicación, entre otros medios de socialización, continúan fortaleciendo la permanencia de estereotipos culturales europeos que desdibujan la imagen del negro, del campesino y del indígena. Esto genera actitudes de discriminación, racismo e inequidad hacia estas comunidades, intolerancia y violencia hacia el colectivo nacional y, a nivel personal, expresiones abiertas de baja autoestima, desarraigo y vergüenza hacia el territorio y la nación. Estas manifestaciones están fomentadas en una mentalidad extranjerizante, que se constituye en una verdadera amenaza a la supervivencia cultural y a la construcción de un proyecto colectivo de nación.

Aunque los textos seleccionados brindan información pertinente sobre el problema abordado se hace necesario descolonizarlos, puesto que presentan en su mayoría la mirada hegemónica que ha tenido Europa sobre los territorios y cuerpos invadidos, colonizados y saqueados.

\section{Referencias}

Arboleda-Quiñonez, Santiago. "Conocimientos ancestrales amenazados y destierro prorrogado: la encrucijada de los afrocolombianos". Web.

Ávila, Rafael. Las nuevas geografías del cuerpo. Bogotá: Universidad Pedagógica Nacional, 2004. Impreso.

Constitución Politica de Colombia, 1991. Web.

De Barañano, Kosme, "Isabel Muñoz: detalles y miradas o los cuerpos como territorio". Art-Signal Contemporany Art Magazine, 1.1 (2002). Web.

De Gracia, Silvio. "Arte Acción en Latinoamérica: cuerpo político y estrategias de resistencia”. Escáner Cultural (2010). Web.

Echeverri, Juan Álvaro. “Territorio como cuerpo y territorio como naturaleza: ¿diálogo intercultural”. Tierra adentro: territorio indígena y percepción del entorno/Surrallés, $A$. y P. García Hierro. Ed. A. Surrallés y P. García-Hierro, 2004. 259-275. Impreso.

Gómez, Marisol. Los hijos del racismo. Bogotá, D.C.2010

Hoffmann, Odile. "Del territorio étnico a la ciudad: las expresiones de identidad negra en Colombia a principios del siglo xxI". Territorio y cultura. Territorios de conflicto y cambio sociocultural (2002): 277-307. Impreso.

Ley de Manumisión o Libertad de Esclavos. 21 de mayo de 1851. Web.

MEN. Decreto 1122. Junio 18 de 1998. Web.

Morales, Inírida. "Mujer negra, mirar del otro y resistencias. Nueva Granada siglo xviı". Memoria y sociedad 7.15 (2003): 53-68. Impreso.

Mosquera, Juan de Dios. “Abolición de la institución de la esclavitud en Colombia y responsabilidades políticas a favor de la población afrocolombiana”. Boletín del Movimiento Nacional Afrocolombiano Cimarrón (2001). Web.

Olson, Sheryl, y Arnold Sameroff, eds.. Biopsychosocial Regulatory Processes in the Development of Childhood Behavioral Problems. Cambridge: Cambridge University Press. 2009. 
Osorio, Myriam. Agencia femenina, agencia narrativa: una lectura feminista de la obra en prosa de Albalucía Ángel. Oxford: Ed. Peter Lang, 2010. Impreso. Hispanic Studies: Culture and Ideas 27.
Vélez, Olga Licia, y María Eumelia Galeano. Investigación Cualitativa. Medellín: Universidad de Antioquia, 2000. Impreso. 